\title{
Comment on "The State of Exosomes Research: A Global Visualized Analysis" and "Current Research Trends in Traditional Chinese Medicine Formula: A Bibliometric Review from 2000 to 2016"
}

\author{
Yuh-Shan Ho \\ Trend Research Centre, Asia University, No. 500, Lioufeng Road, Wufeng, Taichung 41354, Taiwan \\ Correspondence should be addressed to Yuh-Shan Ho; ysho@asia.edu.tw
}

Received 29 April 2019; Accepted 23 August 2019; Published 5 December 2019

Academic Editor: Robert J. Lee

Copyright (c) 2019 Yuh-Shan Ho. This is an open access article distributed under the Creative Commons Attribution License, which permits unrestricted use, distribution, and reproduction in any medium, provided the original work is properly cited.

\begin{abstract}
"The State of Exosomes Research: A Global Visualized Analysis" [1] and "Current Research Trends in Traditional Chinese Medicine Formula: A Bibliometric Review from 2000 to 2016" [2] were recently published in BioMed Research International and Evidence-Based Complementary and Alternative Medicine, respectively.

Wang et al. stated in Section 2.1 that "Publication information from the Web of Science (SCI-Expanded)" and in Section 2.2 that "the research terms" were as follows: theme $=$ exosome $^{*}$ AND publishing year $=($ from 1994 to 2017) AND Language $=($ only English $)$ AND Document types $=($ REVIEW OR ARTICLE)" [1].

Using the methods applied by Wang et al. [1], we found 7,323 publications which are very different from 4,960 in the original paper [1]. To improve the author's method, appropriate keywords should be applied. A total of 7,323 English publications including 5,682 articles and 1,641 reviews were found in SCI-EXPANDED (updated on April 26, 2019) from 1994 to 2017 with keywords such as "exosomes" and "exosome" in the topic including document title, abstract, author keywords, and KeyWords Plus were taken into consideration.

Chen et al. stated in 2.1. Search Strategy that "Papers published from 2000 to 2016 were tracked by the keywords "Traditional Chinese Medicine", "Traditional Chinese Medicine Formula", and "Chinese Herb Formula" for inclusion in analysis and summarization, based on their presence in the Web of Science database [2].
\end{abstract}

Web of Science from 2000 to 2016 were applied as mentioned in the original paper [2]. In total, 42,270 and 20,909 articles were found by using searching keywords (traditional Chinese medicine or traditional Chinese medicine formula or Chinese herb formula) and ("traditional Chinese medicine" or "traditional Chinese medicine formula" or "Chinese herb formula"), respectively. These results show a huge difference ( $57 \%$ of 26,917 articles) from the results in the original paper "A total of 26,917 TCMF-related articles were published in the period from 2000 to 2016" [2]. Furthermore, Chen et al. also stated in Section 2.1 that "it contains more than 12,000 core academic journals with the most influential research fields in natural sciences, engineering technology, and biomedicine" [2]. This information cannot be found in the cited reference [3] in the original paper [2].

Web of Science databases (https://clarivate.com/ products/web-of-science/databases/) includes

(1) Web of Science Core Collection

(2) Specialist Collection

BIOSIS Citation Index

BIOSIS Previews

Biological Abstracts

Zoological Record

MEDLINE

CAB Abstracts, CABI Global Health 
Inspec

FSTA

(3) Regional Collection

Chinese Science Citation Database

Russian Science Citation Index

KCI Korean Journal Database

SciELO Citation Index

(4) Data Collection

Data Citation Index

(5) Patent Collection

Derwent Innovations Index (DII)

Web of Science Core Collection: Citation Indexes includes

(1) Science Citation Index Expanded (SCIEXPANDED)

(2) Social Sciences Citation Index (SSCI)

(3) Arts and Humanities Citation Index (A\&HCI)

(4) Conference Proceedings Citation Index-Science (CPCI-S)

(5) Conference Proceedings Citation Index-Social Science and Humanities (CPCI-SSH)

(6) Book Citation Index-Science (BKCI-S)

(7) Book Citation Index-Social Sciences and Humanities (BKCI-SSH)

(8) Emerging Sources Citation Index (ESCI)

Web of Science Core Collection: Chemical Indexes

(1) Current Chemical Reactions (CCR-EXPANDED)

(2) Index Chemicus (IC)

Web of Science Core Collection includes multidisciplinary information from over 18,000 high-impact journals, over 180,000 conference proceedings, and over 80,000 books from around the world (https://clarivate.com/products/webof-science/databases/).

Authors should choose appropriate databases based off of their topic instead of choosing random databases for their bibliometric research. For instance, Emerging Sources Citation Index (ESCI) complements the highly selective indexes by providing earlier visibility for sources under evaluation as part of SCIE, SSCI, and A\&HCI's rigorous journal selection process (http://liu.brooklyn.libguides.com/ az.php?a=e). Web of Science Core Collection: Chemical Indexes as well as SSCI, A\&HCI, ESCI, CPCI-S, CPCI-SSH, BKCI-S, and BKCI-SSH are inappropriate for "Current Research Trends in Traditional Chinese Medicine Formula: A Bibliometric Review from 2000 to 2016" [2].

The SCI-EXPANDED is designed mainly for researchers to find published literature studies, not for bibliometric studies [4-6]. Thus, it is always necessary to use an accurate bibliometric treatment when using the Web of Science database [4-6]. Fu and Ho [7] pointed out that the documents, which can only be searched out by KeyWords Plus, were irrelevant to "exosomes" in Wang et al.'s paper [1] and "traditional Chinese medicine formula" in Chen et al.'s paper [2]. Due to biases by using SCI-EXPANDED for bibliometric studies, Ho's group was the first to propose "front page" (including the article title, the abstract, and the author keywords) as a filter to improve the bibliometric method [8-10].

In the case of Wang et al.'s paper [1], 1,371 publications (19\% of the 7,323 publications) did not contain searching keywords ("exosomes" and "exosome") in their "front page". For instance, classic article [11] with 1,000 or more total citations from Web of Science Core Collection since publication to the end of the most recent year, "The MicroRNA spectrum in 12 body fluids" [12]; and highly cited articles [13] with 100 or more total citations "Initial genome sequencing and analysis of multiple myeloma" [14] and "Secreted monocytic miR-150 enhances targeted endothelial cell migration" [15].

In the case of Chen et al.'s paper [2], after our pre-study, one appropriate method is to use SCI-EXPANDED with searching keywords ("Chinese medicine formula" or "Chinese medicine formulas" or "Chinese medicine formulation" or "Chinese medicine formulations" or "Chinese medicine formulae" or "Chinese herb formula" or "Chinese herb formulas" or "Chinese Herb Formulation") from 2000 to 2016. Document type of "article" was considered. This method resulted in 315 articles. Altogether, 310 articles (98\% of the 315 articles) had searching keywords in their "front page" and five articles (1.6\% of the 315 articles) had no any searching keywords in their "front page".

Furthermore, typical evidence was found in Table 7 [1]. The top 20 highly cited Traditional Chinese Medicine Formula-related articles were found in Chen et al.'s original paper [2]. Some articles did not include "formula" in their "front page" in Table 7 in the original paper [1]; for example, highly cited article entitled "Multiple chromatographic fingerprinting and its application to the quality control of herbal medicines" [16]; "Comparative pharmacokinetics of baicalin after oral administration of pure baicalin, Radix scutellariae extract and Huang-Lian-Jie-Du-Tang to rats" [17]; and "An approach to develop two-dimensional fingerprint for the quality control of Qingkailing injection by high-performance liquid chromatography with diode array detection" [18].

Published articles by for example Li and Nan [19], Liu and Liao [20], Liang and Liu [21], Li et al. [22], and Gao and Ruan [23] with the same problem can also be found in recent years. In order to stop the proliferation of the problem, comments have been made in Environmental Science and Pollution Research [4], Renewable and Sustainable Energy Reviews [24], Journal of Soils and Sediments [6], and Journal of Foot and Ankle Surgery [25]. However, the same problem is constantly being presented by authors and published by journals such as International Journal of Environmental Research and Public Health [26, 27], Sustainability [28, 29], Journal of Cleaner Production [30, 31], and Environmental Science and Pollution Research [32, 33]. Editors might reject similar comments like this. However it is more important to stop publishing papers with the same problem, at the same 
time, letting authors and readers know the serious problem behind these published papers.

Wang et al. [1] and Chen et al. [2] used inappropriate methods to publish bibliometric papers in BioMed Research International and Evidence-Based Complementary and Alternative Medicine. This may result in misleading readers of the journals. From my prospective, authors should have used an appropriate bibliometric method and filter for their studies, thereby providing greater accuracy results for their bibliometric studies.

\section{Conflicts of Interest}

The authors declare no conflicts of interest.

\section{References}

[1] B. Wang, D. Xing, Y. Y. Zhu, S. Dong, and B. Zhao, "The state of exosomes research: a global visualized analysis," BioMed Research International, vol. 2019, Article ID 1495130, 10 pages, 2019.

[2] Y. B. Chen, X. F. Tong, J. Ren, C. Q. Yu, and Y. L. Cui, "Current research trends in traditional chinese medicine formula: a bibliometric review from 2000 to 2016," EvidenceBased Complementary and Alternative Medicine, vol. 2019, Article ID 3961395, 13 pages, 2019.

[3] J. I. de Granda-Orive, A. Alonso-Arroyo, and F. RoigVázquez, “¿Qué base de datos debemos emplear para nuestros análisis bibliográficos? Web of Science versus SCOPUS," Archivos de Bronconeumología, vol. 47, no. 4, p. 213, 2011.

[4] Y.-S. Ho, "Comments on "mapping the scientific research on non-point source pollution: a bibliometric analysis" by Yang et al. (2017)," Environmental Science and Pollution Research, vol. 25, no. 30, pp. 30737-30738, 2018.

[5] Y. S. Ho, "Comment on: "a bibliometric analysis and visualization of medical big data research" sustainability 2018, 10, 166," Sustainability, vol. 10, no. 12, Article ID 4851, 2018.

[6] Y.-S. Ho, "Bibliometric analysis of insights into soil remediation," Journal of Soils and Sediments, vol. 19, no. 10, pp. 3657-3658, 2019.

[7] H.-Z. Fu and Y.-S. Ho, "Top cited articles in thermodynamic research," Journal of Engineering Thermophysics, vol. 24, no. 1, pp. 68-85, 2015.

[8] H.-Z. Fu, M.-H. Wang, and Y.-S. Ho, "The most frequently cited adsorption research articles in the Science Citation Index (Expanded)," Journal of Colloid and Interface Science, vol. 379, no. 1, pp. 148-156, 2012.

[9] H.-Z. Fu and Y.-S. Ho, "Top cited articles in adsorption research using Y-index," Research Evaluation, vol. 23, no. 1, pp. 12-20, 2014.

[10] Y.-S. Ho and H.-Z. Fu, "Mapping of metal-organic frameworks publications: a bibliometric analysis," Inorganic Chemistry Communications, vol. 73, pp. 174-182, 2016.

[11] X. Long, J.-Z. Huang, and Y.-S. Ho, "A historical review of classic articles in surgery field," The American Journal of Surgery, vol. 208, no. 5, pp. 841-849, 2014.

[12] J. A. Weber, D. H. Baxter, S. Zhang et al., "The MicroRNA spectrum in 12 body fluids," Clinical Chemistry, vol. 56, no. 11, pp. 1733-1741, 2010.

[13] Y.-H. E. Hsu and Y.-S. Ho, "Highly cited articles in health care sciences and services field in science citation index expanded," Methods of Information in Medicine, vol. 53, no. 6, pp. 446458, 2014.
[14] M. A. Chapman, M. S. Lawrence, J. J. Keats et al., "Initial genome sequencing and analysis of multiple myeloma," Nature, vol. 471, no. 7339, pp. 467-472, 2011.

[15] Y. Zhang, D. Liu, X. Chen et al., "Secreted monocytic miR-150 enhances targeted endothelial cell migration," Molecular Cell, vol. 39, no. 1, pp. 133-144, 2010.

[16] X.-H. Fan, Y.-Y. Cheng, Z.-L. Ye, R.-C. Lin, and Z.-Z. Qian, "Multiple chromatographic fingerprinting and its application to the quality control of herbal medicines," Analytica Chimica Acta, vol. 555, no. 2, pp. 217-224, 2006.

[17] T. Lu, J. Song, F. Huang et al., "Comparative pharmacokinetics of baicalin after oral administration of pure baicalin, Radix scutellariae extract and Huang-Lian-Jie-Du-Tang to rats," Journal of Ethnopharmacology, vol. 110, no. 3, pp. 412-418, 2007.

[18] S. K. Yan, W. F. Xin, G. A. Luo, Y. M. Wang, and Y. Y. Cheng, "An approach to develop two-dimensional fingerprint for the quality control of Qingkailing injection by high-performance liquid chromatography with diode array detection," Journal of Chromatography A, vol. 1090, no. 1-2, pp. 90-97, 2005.

[19] X. Li and R. Nan, "A bibliometric analysis of eutrophication literatures: an expanding and shifting focus," Environmental Science and Pollution Research, vol. 24, no. 20, pp. 1710317115, 2017.

[20] W. Liu and H. Liao, "A bibliometric analysis of fuzzy decision research during 1970-2015," International Journal of Fuzzy Systems, vol. 19, no. 1, pp. 1-14, 2017.

[21] T.-P. Liang and Y.-H. Liu, "Research landscape of business intelligence and big data analytics: a bibliometrics study," Expert Systems with Applications, vol. 111, pp. 2-10, 2018.

[22] N. Li, R. Han, and X. Lu, "Bibliometric analysis of research trends on solid waste reuse and recycling during 1992-2016," Resources, Conservation and Recycling, vol. 130, pp. 109-117, 2018.

[23] C. Gao and T. Ruan, "Bibliometric analysis of global research progress on coastal flooding 1995-2016," Chinese Geographical Science, vol. 28, no. 6, pp. 998-1008, 2018.

[24] Y. S. Ho, "Comments on "past, current and future of biomass energy research: a bibliometric analysis" by Mao et al. (2015)," Renewable \& Sustainable Energy Reviews, vol. 82, pp. 42354237, 2018.

[25] Y. S. Ho, "Some comments on: Zha et al. "a bibliometric analysis of global research production pertaining to diabetic foot ulcers in the past ten years", "Journal of Foot \& Ankle Surgery, vol. 58, pp. 253-259, 2019, In press.

[26] X. M. Ma, L. F. Zhang, J. Q. Wang et al., "Knowledge domain and emerging trends on echinococcosis research: a scientometric analysis," International Journal of Environmental Research and Public Health, vol. 16, no. 5, Article ID 842, 2019.

[27] Y. Qi, X. Y. Chen, Z. Hu et al., "Bibliometric analysis of algalbacterial symbiosis in wastewater treatment," International Journal of Environmental Research and Public Health, vol. 16, no. 6, Article ID 1077, 2019.

[28] J. G. Shi, W. Miao, and H. Y. Si, "Visualization and analysis of mapping knowledge domain of urban vitality research," Sustainability, vol. 11, no. 4, Article ID 988, 2019.

[29] S. H. Shin, O. K. Kwon, and X. Ruan, "Analyzing sustainability literature in maritime studies with text mining," Sustainability, vol. 10, no. 10, Article ID 3522, 2018.

[30] H. Yu, Y. Wang, X. Li, C. Wang, M. Sun, and A. Du, "Measuring ecological capital: state of the art, trends, and challenges," Journal of Cleaner Production, vol. 219, pp. 833-845, 2019. 
[31] H. Si, J.-g. Shi, G. Wu, J. Chen, and X. Zhao, "Mapping the bike sharing research published from 2010 to 2018: a scientometric review," Journal of Cleaner Production, vol. 213, pp. 415-427, 2019.

[32] X. Li, J. Du, and H. Long, "Dynamic analysis of international green behavior from the perspective of the mapping knowledge domain," Environmental Science and Pollution Research, vol. 26, no. 6, pp. 6087-6098, 2019.

[33] Q. Wu, J. Hao, Y. Yu et al., "The way forward confronting ecoenvironmental challenges during land-use practices: a bibliometric analysis," Environmental Science and Pollution Research, vol. 25, no. 28, pp. 28296-28311, 2018. 


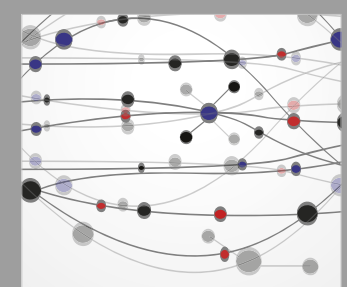

The Scientific World Journal
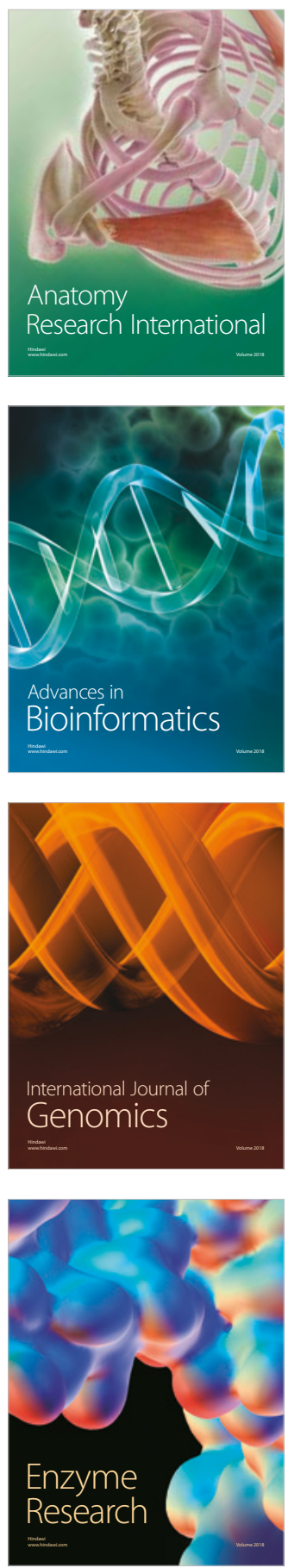
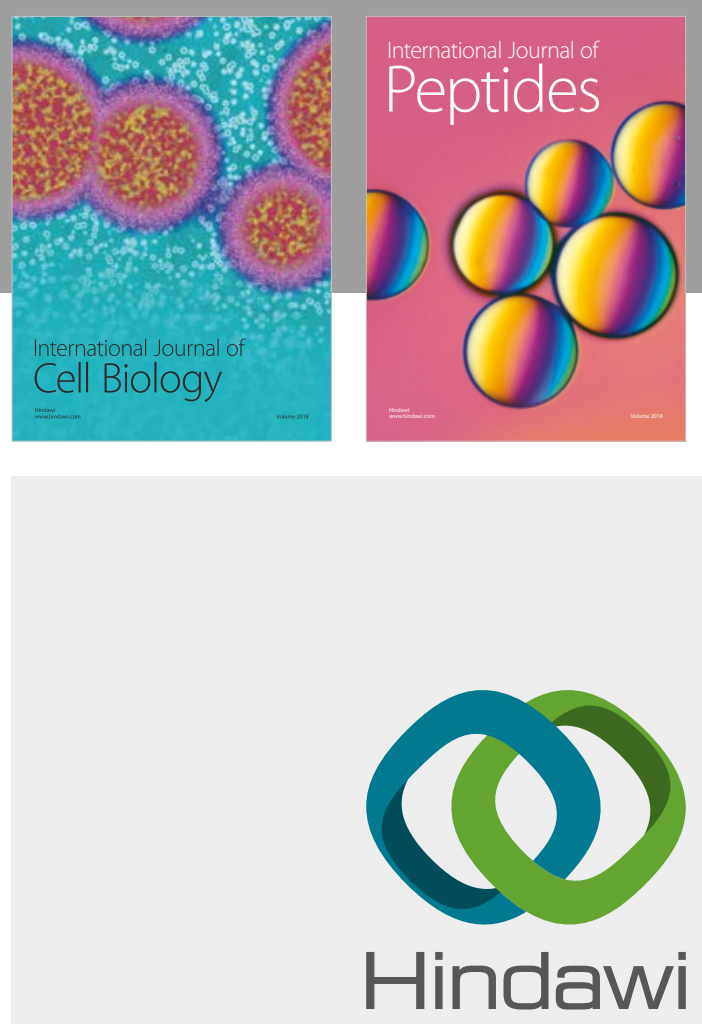

Submit your manuscripts at

www.hindawi.com
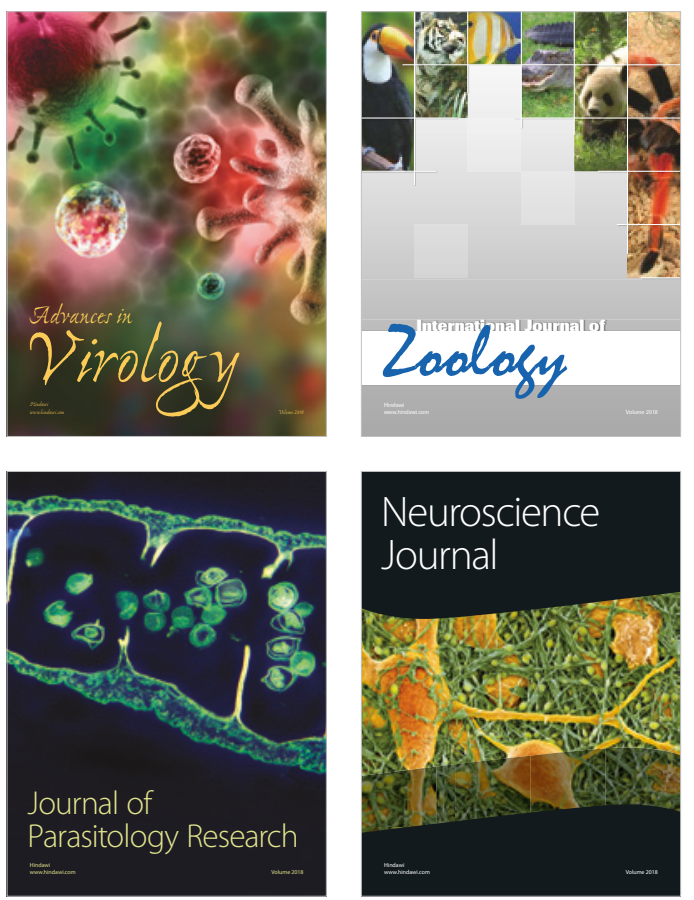
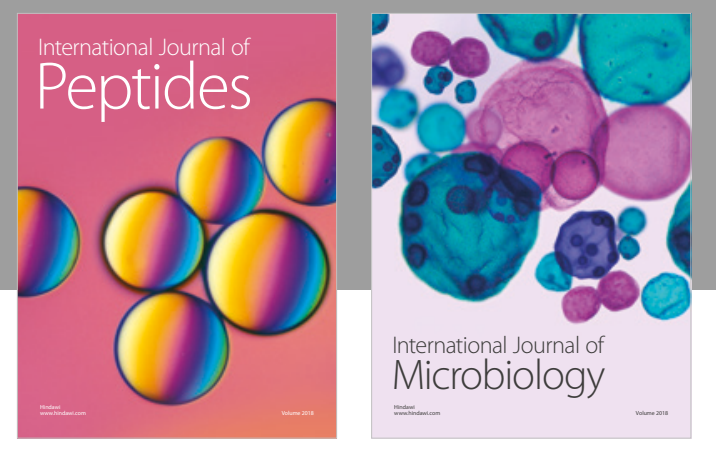

nternational Journal of Microbiology
Journal of
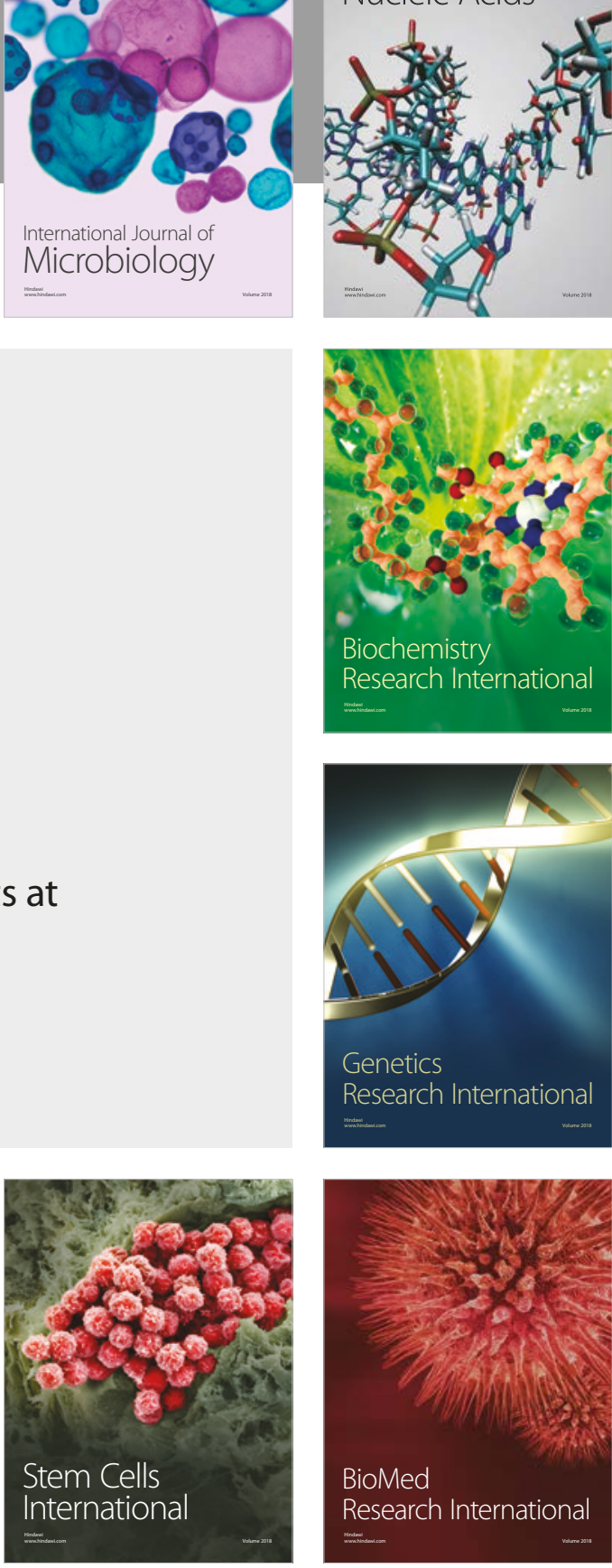
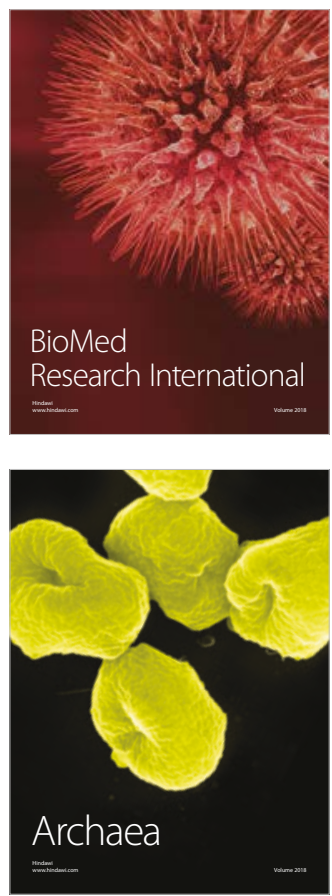